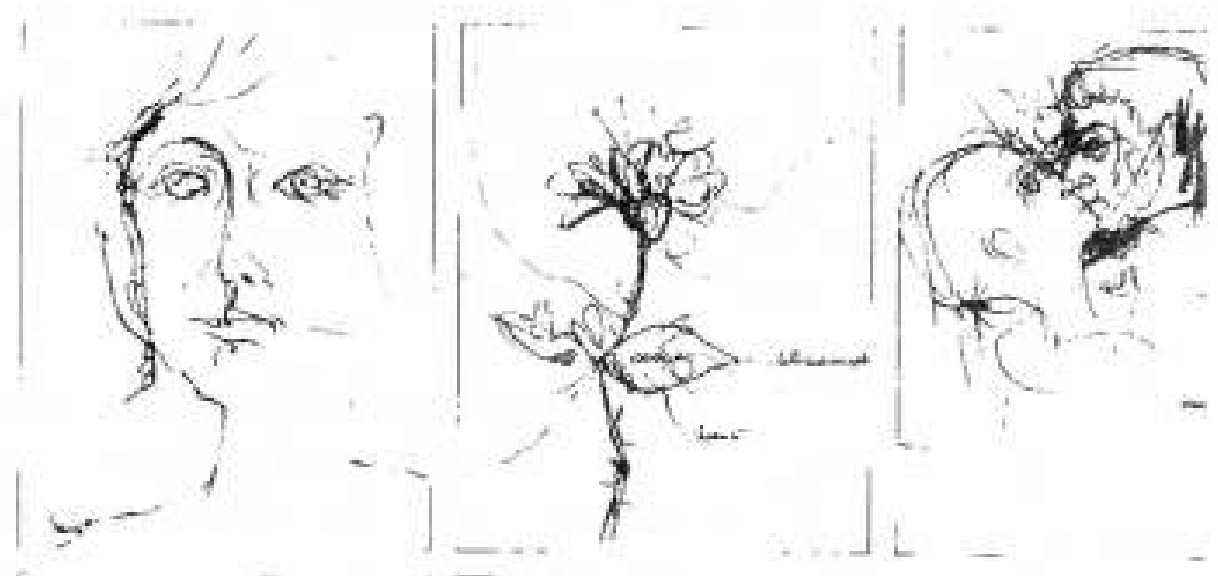

\title{
PERFIL PARA UNA DIRIGENCIA INTEGRAL EN LOS ESCENARIOS EDUCATIVOS
}

\section{CARLOS ALBERTOGONZALLEZQUITIAN}

Arquitecto, Magister en Educación y Desarrollo Social Profesor Universidad Nacional de Colombia. Sode Manizales RUBÉN DARIOCHICA

Magister en Educacion y Desarrollo Social a dirigencia integral es una acción de liderazgo comprometida y significada en torno a la colectividad y al proceso educativo; se fundamenta en la Gerencia Integral Creativa.' definida como la orientación, facilitación y acompariamiento de procesos, para la generación y desarrollo de nuevas y mejores alternativas de integración de todas las dimensionalidades que componen una organizacion o sistema, intervenidos por sus actores sociales. el medio y la cultura, a través de una acción directiva y paradirectiva. Se orienta a guiar los esfuerzos hacia 
el logro de objetivos trazados dentro de una visión mancomunada, canalizada mediante una acción y clima creativo, tal que promuevan, fomenten el talento y motiven a los individuos al logro con la utilización plena de sus capacidades $y$ habilidades cognitivas, afectivas, volitivas y conativas; $y$ que por otra parte se incorporen a una acción de verdadero equipo. que como conjunto generen una memoria y visión colectiva, en la cual la integración de habilidades y saberes configuran un efecto multiplicador donde el conjunto ofrece un producto mayor que la suma de la producción de las partes.

La acción paradirectiva se concibe como el liderazgo centrado en la armonización y optimización de recursos. la interacción con el medio y la participacion plena de los actores sociales. Se concibe aqui al maestro como agente social y como promotor de la comunidad educativa. que cjerce además de fiderazgo en los roles de la administración educativa. un papel paradirectivo de acompanamiento en los procesos de aprendizaje y construcción del conocimiento, es un liderazgo social de amplia cobertura dirigido a todos los niveles, tanto en los cargos de dirección, como a la gerencia de la propia actividad o desempeño profesional de la persona en el campo de su especialidad. a la gerencia de si mismo en el ejercicio educativo y a su compromiso de transformación social.

Las acciones de dirigencia educativa se encaminan a la producción. construcción y aprehensión del conocimiento, integrado a la misión de desarrollo humano, en sus diferentes dimensiones: afectiva. cognoscitiva, comunicativa, valoral, formativa, productiva, lúdica y politica. Es integral al concepto de educación identificado por la participación significada y deliberante de los diversos actores, por ser una práctica de responsabilidad del colectivo social, por destacarse en escenarioS de reflexión de pensamiento y construcción de conocimiento, por su determinada pretensión de transformación, innovación y desarrollo.

Ladirigencia integral en educación se concibe como un ejercicio creativo, como una acción fertilizante para desarrollo humano y el bienestar social en todas sus dimensiones:

Afectiva, en búsqueda de identidad, seguridad y estima.

Cognoscitiva, como fortalecimiento de habilidades de pensamiento, desarrollo de formas y estilos cognitivos, formulación y resolución de retos.

Comunicativa, en búsqueda de diálogo. argumentación y entendimiento.

Ético-Valoral, con fundarnento en su función social y los valores.

Productiva, orientada hacia la elaboración, innovación y el logro.

Formativa, en busqueda del aprendizaje significativo. el conocimiento. la visión y la prospectiva.

Lúdica, a través de la posibjlidad. el juego y el disfrute.

Politica, en büsqueda del clima organizacional, la convivencia y el equilibrio. 


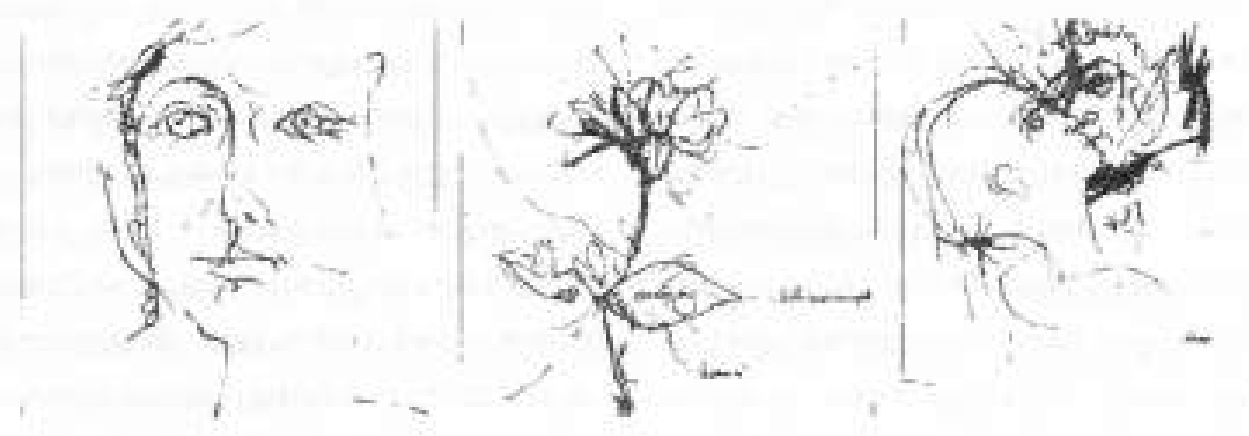

El Desarnollo Humano, orientado por la estrategia creativa, que utiliza los métodos de pensamiento divergente, centrados en la posibilidad y fertilidad de ideas con la apropiación de técnicas creativas con miras a una transformación, dirigida al conjuro de la crisis universal mediada por el desarrollismo y ta competencia, y al logro de una mejor calidad de vida del individuo y la colectividad; deberá ser un producto creativo, de la misyor novedad, pertinencia y relevancia, que conduzca a la construcción a partir del conflicto y de la crisis, que convierta las situaciones de desequilibrio en oportunidad, y que con su divergencia e integralidad. logre impactar al individuo. a la organización y al medio.

El ejercicio de dirigencia será visto, desde luego, en los diferentes niveles del acto creativo: desde el nivel primario de la expresión y transmisión de la información, hasta los más altos niveles de invención $e$ innovacion: desde la dimensión de la vida cotidiana hasta los ámbitos de mayor especialidad en los proceso de conocimiento: desde los niveles primarios de planeación y ordenamiento hasta la disposición de complejos sistemas para el logro de grandes cometidos contextuados en el medio político. económico y social.

En este sentido de cobertura e integralidad, la dirigencia en educación se identifica también con la concepción de Gerencia Integral (Sallenave 1991) 2. la cual se entiende como la planeación y gestión significada y contextuada, mediada por la cultura, la organización y la estrategia; entendiendo por cultura. todo lo que nos implica y nos referencia, por organizacion, todo lo que nos relaciona. y por estrategia, el entramado y la calidad de dichas relaciones, El dirigente integral desde esta perspectiva. debe ser gestor, organizador y estratega; conocedor impregnado del medio y forjador de futuros. dinamizador de procesos interactivos al interior $y$ exterior de su núcleo. y promotor creativo en la gestación y desarrollo de ideas nuevas y valiosas. que le permiten asi mismo y al grupo humano que lo rodea, la educación, la trascendencia y el logro eficiente a través de la acción.

A la dirigencia, de acuerdo con este planteamiento. la caracteriza un liderazgo creativo, el cual estả defunido por la prospectiva del orientador, que vislumbra poderes colectivos. provoca y facilita la proyeccion de su equipo. administra la construcción de visiones y emociones comunes; convocando y provocando la reflexión permanente en la acción. encaminada hacia la plenitud del ejercicio individual y el beneficio colectivo. En este campo. el dirigente se convierte más en un constructor de emociones y creador de escenarios, caminos y mundos posibles. que en un director o guía.

Asi mismo. el dirigente educativo tiene que concebirse como un germen de cultura y organización. caracterizado por su interés y empeño permanen- 
tes, por la emoción por el conocimiento, por ser ejemplo de vida, agente y promotor de un núcleo identificado por el trabajo en equipo y por su comunicación en una dinámica participativa y deliberante. fundamentada en el diälogo y la argumentaciỏn. Tambièn se concibe como un facilitador y provocador de retos, que parte del ejercicio de preguntarse por si mismo y por el significado de lo que hace

Para completar la caracterización integral y creativa del dirigente educativo es necesario conccbirlo, además de lider y organizador, como estratega. Con dominio y conocimiento de la didáctica y de los procesos de aprehensión. con los cuales integra el ser en el saber y el cómo ser se destaca su actuación, por la amonización de las potencialidades individuales y colectivas, por el manejo del contexto. materializadoen la optimización de los recursos y escenarios de acción. Esta gestión involucra la utilizaciòn plena e intencionada de las capacidades de más alto orden tanto del maestro como de sus alumnos, en la planeación y

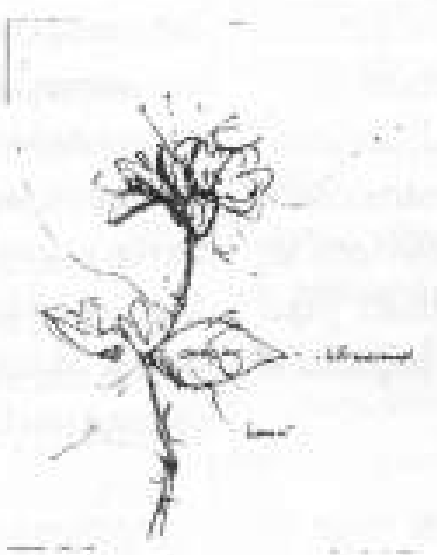

desarollo de acciones significativas, aprovechamiento que puede darse mediante el empleo permanente de activadores creativos en un proceso de permanente innovación ${ }^{7}$, los cuales buscan ofrecer procesos creativos mediante guias para la formulación y solución de problemas. $y$ a su vez aportan métodos alternativos de potencionalidad humana. basados en el pensamiento analógico. combinatorio y critico-reflevivo.que se materializan en la aplicación de tecnicas y ejercicios para la producción creativa.

\section{ACCION DIRIGENTE}

En la concepción del maestro como dirigente edu- cativo, se destacan tres roles fundamentales en el ejercicio de su función: la de orientador. facilitador y acompañante. Orientador como profesional en un ärea especifica del conocimiento, que provee la experiencia, la visión de conjunto y la visión retrospectiva de campo en el proceso de acercamiento. recreación y construcción del conocimiento dentro de un universo determinado de estudio. Facilitador para la provocación de actos comunicativos. aprehensión del conocimiento y diseminación del mismo, mediante la recreación y construccion del conocimiento por parte del alumno como protagonista. Didacta para los procesos que faciliten un aprendizaje significativo y una formación integral, agente que provee los materiales, las herramientas y los instrumentos, para cimentar y edificar el conocimiento en el es: tudiante como actor principal del mismo.

El acompantante, como agente próximo. como actor social y sujeto participedel ejercicio educativo, educador y lider que sigue a sus discipulos. que hace parte de su organización, proyectos y expectativas. Coprotagonista de las acciones ensefiantes y acompañante de servicio y apoyo de los procesos de aprendizaje en los momentos, acciones y emociones. en los que se construye el saber.

Su particularidad como mediador y como actor social en el acto educntivo, sumada a su función como orientador facilitudor y acompañante. le implica una responsabilidad social en cunnto: ${ }^{4}$

Es quien ha trasitado y se ha especializado por ese camino, y por lo tanto lo conoce. Es la persona que como simboloe imagen inspira y motiva. Fs parte. como también responsable del ambiente que debe 
ofrecer confianza y seguridad. Es quien conoce y articula el ritmo y tiempo personales de cada uno de los integrantes del grupo constituyéndolo en un todo. Es quien conoce las necesidades y expectativas de los participantes, el momento del proceso en que se encuentra, y el estado de desarrollo de cada uno de ellos. Es el guia que orienta el descubrimiento de valores universales y campos especificos. Es elencargado de lograr un clima de confianza para la comunicación y el diálogo. Es portador y receptor de la información. centro de sentimientos, gustos y vivencias. Es el responsable de los hechos y sucesos acaecidos en el grupo, su presencia ofrece efecto significativo en el comportamiento y conducta de los participantes. Es quien planifica, programa y evalúa los procesos de planificación, programación y evaluación dentro del grupo. Es quien conoce y dispone con mayor cobertura de los recursos e instrumentos de trabajo. Es quien se ha comprometido explicitamente a estar al frente del proceso y a servir de apoyo. Es quien con mayor madurez y recurso es capaz de autoevaluarse para evaluar y retroalimentar el proceso de si mismo. de los participantes y del grupo.

A. González.(1992), propone para un ambiente y atmósfera creativa como condiciones del facilitador las siguientes ${ }^{5}$ :

- Tener conocimientos teóricos y prácticos sobre la creatividad.

- Conocer. seleccionar y usar estrategias apropiadas para estimular el proceso creadot.

- Saber trabajar en grupo. Manejar técnicase instrumentos de trabajo grupal.

- Saber como facilitar la comunicación entre los miembros para la solución de problemas.

- Dominio sobre situaciones surpresivas, manejo de hechos y situaciones inesperadas.

- Saber autoevaluar su estilo como conductor facilitador, ser consciente de sus ventajas y debilidades, asi como de la utilización de la estrategia apropiada

- Ser constantemente abierto y receptivo a la retroalimentación que le ofrece el grupo sobre su propio desempeño. asi como la que le ofrecen sus otros colegas.

- Demostrar al grupo seguridad y dominio en el manejo de la realimentación mediante cambios personales.

- Saber detectar y manejar los diferentes ritmos de los individuos y del grupo.

- Ser ejemplo de accion y conducta para la creatividad, proyectando una imagen de seguridad. innovación y competencia ante la tarea.

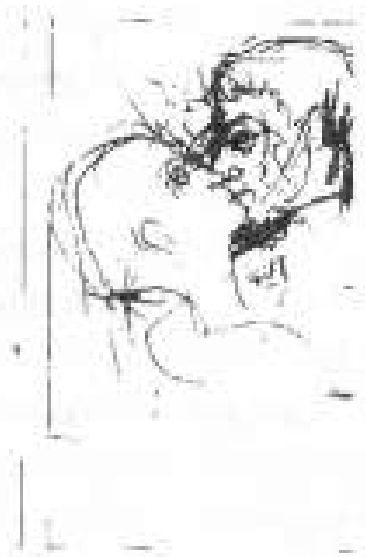

Las condiciones de responsabilidad. los planteamientos de facilitación reflexiva y los retos como acompanante están mediados por el perfil personológico y estilo de dirigencia que ofrece el maestro como actor social del proceso educativo. El estilo de dirigencia tiene que ver con losestilos cognitivos del maestro, $y$ las maneras particulares como éste ejerce sus interacciones. Dependiendo del estilo cognitivo y de interacción. se establecen diversas formas de dirección y acompañamiento, reflejadas en tipologias particulares de dirigencia ${ }^{e}$.

K.Gretz y y S.Drozdeck (1993), plantean dos rasgos primarios desde lo actitudinal para examinar las tendencias de dirigencia: el rasgo polar de lider y el rasgo polar de seguidor. estos dos rasgos. en su conjunto, caracterizarian la acción de un dirigente. mediada a su vez por dos actitudes de modificación: la hostil y la amistosa. Éstos términos de pola- 


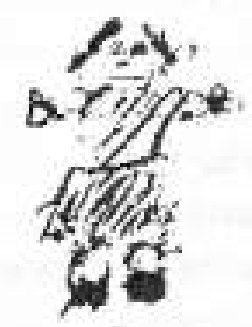

ridad y modificación implican orientaciones generales sobre como se comportan las personas en su relación social con la gente dentro de un núcleo, en una atmósfera productiva?. Esta propuesta podría ser util, no tanto para calificarse o retratarse en estas tendencias, pero si para reflexionar sobre los estereotipos que de una manera u otra. con mayor frecuencia nos vemos reflejados en nuestra dirigencia educativa,

Se plantean en esta estructura diferentes escalas al interior de las polaridades básicas entre Lider y Seguidor. ofreciendo distintas tendencias de rasgo,e igualmente sucede con los modificadores, Hostil y Amistoso, con lo cual se establece un juego posicional gravitatonio multivariado, que identifica al sujeto de acuerdo con el lugar que ocupe con relación a la polaridad y con la modificabilidad. Es bueno aclarar que no existe una persona exclusivamente posicionada en el extremo de una polaridad. puesto que el sujeto es de todas formas influenciado de alguna manera por la polaridad opuesta; esto nos ofrece perfiles flexibles y variedad de matices, aunque todos ellos con denotadas tendencias de rasgoy modificabilidad.

Las polaridades lider y seguidor. como el hostil y sociable. vistas aisladamente se contraponen y se presentan como una expresión radical de una tipologia determinada en la realidad: como se ha expresado no aparecen solas o exclusivas. Estas po- laridades son sólo extremos, que ubican actitudes y conductas particulares y ayudan a configurar la mirada del agente social de acuerdo con sus actuaciones e interacciones, La polaridad nos ofrece una imagen de referencia, pero no retrata o especifica a un individuo en particular. Cualquier sujeto está mediado por las dos polaridades y los dos modificadores, que lo situará en determinada posición y que le permitirá identificarse contextuadamente frente a sus actuaciones, lectura que es necesario elevar a conciencia y someterla a reflexión en los escenarios de dirección y gestión educativat. puesto que el dirigente no se concibe aislado del grupo que dirige. $y$ de hecho, su actuación se constituye en elemento mediador del proceso formativo.

Las polaridades y modificadores propuestos por Gretz y Drozdeck, traspolados al medio educativo. se interpreta que están determinados por un conjunto de caracteristicas predominantes.

Los lideres, plantean, se caracterizan por su sentido de autoridad y autonomia. En general sienten la necesidad de mantener control en sus relaciones personales y el deseo permanente para ser mejores. cultivan la iniciativa y firmeza en las decisiones, se caracterizan por ser determinados independientes. emprendedores, focalizadores de metas y logros. gestores de procesos mediados por la automotivaciòn y el compromiso. Tienden a ser dedicados $y$ arriesgados, algunas veces obsesivos y absorbentes, ventajosos y utilitaristas.

Los seguidores muestran una disposición de servicio para actuar a partir de iniciativas externas, para colaborar con la fucrza impulsiva de otros. lo que contempla un conjunto de rasgos, entre ellos la dependencia, la adherencia, el acompantamiento. el apoyo, aunque esto también conduce algunas veces a la indecisión, a la pasividad y a la falta de 
asertividad. Los seguidores tienden a ser utilizados y controlados por los demás dada su condición de identidad con propósitos y acciones y su permanente solidaridad y colaboración, asi mismo prefieren evitar los enfrentamientos personales, se esmeran en cumplir deseos, canalizan su motivación en pos de las metas y expectativas de personas de su polaridad opuesta.

La actitud hostil se manifiesta en individuos formados generalmente en escenarios de choque, muestran gran ansiedad de logro, en algunos casos son personas incomprendidas, frustradas o aisladas, suelen provenir de ambientes de formación agresivos, con ausencias de afecto o marcada manipulación del mismo. Tienden a un comportamientoestoico, a cumplir metas independientemente del precio, comunican temor y admiración por su fuerza, valor extremo, expresan a veces falta de aprecio por la gente. tienden a levantar barreras en la comunicación y a centrarse en si mismos. Ofrecen una imagen de indiferencia ante sus otros e insensibilidad ante sus necesidades e ideas, este tipo de personas en su núcleo a menudo se resisten a la colaboración. suelen ser frios en sus relaciones. con tendencia a la manipulación, muestran un profundo egocentrismo, se radicalizan como vencedores o vencidos y se caracterizan por anteponer sus intereses personales. La hostilidad los lleva a ser emprendedores y determinados, a lograr metas y propositos soportando la indiferencia o las vicisitudes, a transitar y dominar caminos tortuosos, a soportar las crisis y a mantener el coraje y el arrojo.

La actitud amistosa muestra gran afinidad con los demás. Un interés de integración y relación, implica, en las acciones, ef reconocimiento del valor y dignidad de las personas, una gran sensibilidad a las necesidades y expectativas de los demás. En términos de dirección y acompañamiento, podria definirse esta actitud como el grado de preocupación por la relación conel otro y laperceptividad y sensibilidad ante sus necesidades; refleja confianza y unaractitud de ganancia mutua y de interés por el colectivo. Tiende a fundir diversión y trabajo. confundir metas, evadir responsabilidades, a no distinguir prioridades e importancias.

\section{PERFILES COMBINADOS DE DIRIGENCIA}

El perfil real del dirigente se forja en la combinación de los rasgos descritos anteriormente, provenientes de las diferentes polaridades, con la mediación de los modificadores señalados. los matices se materializan a través de una matrizque permite el entramado. La combinación de los rasgos básicos de la dirigencia: Lider-Seguidor, con los modificadores Hostil-Amistoso, ofrecen un sistema de perfiles psicológicos asociados. ${ }^{\text {X }}$

La combinación de Lider y Hostil nos ofrece la visión del Dictador. Esta polaridad se fundamenta en el dogmatismo y en el convencimiento de poseer la verdad y la razon. Trata de imponer su voluntad, de trasmitir su saber, insiste en ejercer el control y tiende a subvalorar la opinión de los demás, más que todo sobre los que ejerce dominio y son sus subordinados. Prevalece la posición del yo. y la decisión fundada en el parecer personal e individual. se suele presentar agresivo cuando se salen los hechos de su

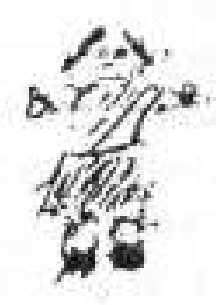


canal previsto o se manifiestan sentimientos de incomprensión por parte de sus colaboradores y subordinados.

Tradicionalmente la polaridad dictatorial ba sido la más frecuente en los procesos de dirigencia educauiva convencional, que se distingue y fortalece en la autoridad. la posesión del conocimiento, manejo y dominio unilateral del saber. Se ampara en la ensenanza como fruto de la experiencia y la autoridad que ofrece el saber y el conocer. Se fomenta en esta polaridad la competencia y la solución de retos. el premio y el castigo por el fracaso. Se identitica con el esfuerzo, el espiritu competitivo y el acierto. Aunque ha menguado esta tendencia con los avances de la reflexión pedagógica hoy en dia. si-

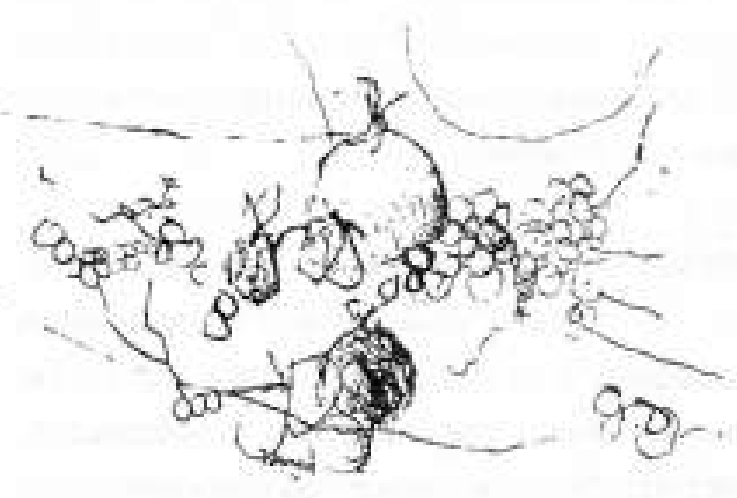

gue siendo un factor importante oun fin en algunos medios y procesos formativos.

Ina razon por la cual se ha persistido en esta actitud, es el paradigma de la educación centrada en el profesor como actor protagónico y depositario del conocimiento, el docente como centro y fuente de saber. Esto lo eleva a la categoria de imagen y de juez supremo, en la mayoria de los casos lo convierte en dictador. El dictador tipico tiende a hacer las cosas a su manera y a estar convencido de ellas. se acostumbra a abrirse camino sin importar los obstáculos y sin examinar los medios, exige lealtad y aceptación total de sus órdenes, manifiesta permanentemente el poder de su investidura y la utiliza como instrumento de conducción apoyado en la experiencia, el conocimiento y el cumplimiento de su deber. El dictador tiende a suponer que la estrategia más adecuada de motivación y desarrollo es el premio y el castigo, y que el recurso para el logro es la presión y la opresión. El premio en el aula de clase suele estimarse en la nota de calificación y en las dádivas otorgadas a los subordinados de acuerdo con los niveles de desempeño esperados por el profesor.

En la consecución de logro bajo su mando, cl dictador expresa sentimientos ambivalentes ante el grupo que dirige: en la medida que el desempeño de sus subordinados le favorece. se enorgullece de ellos. Pero también puede verse amenazado por la posibilidad de que el grupo se salga de control. sobresalga, o tome conciencia de su autonomia sobrepasando los limites de su poder y territorio. Esta condición se transforma en una amenaza que ronda su posición. Frecuentemente ataca cualquier idea que no sea la de su interés o proposición que se formule diferente a lo que espera escuchar. Cuando recibe criticas o frutos no deseados contrarios a las metas y los objetivos por él propuestos, normalmente culpa al grupo o a las circunstancias por los hechos y efectos negativos.

Si por el contrario es exitoso en sus propositos. acapara y centra los elogios para si. generalmente sin reconocimiento de los participantes. Tiende a centrar el proceso educativo en la acción enseñante y depositaria del saber. $y$ el logro en acciones de exigencia. autoridad y disciplina. De hecho, reitero. este perfil es un extremo. y esta polaridad no se materializa en un dirigente en particular. en el más 
critico de los casos, sólo marca la tendencia del dirigente haciaella.

La combinación del rasyo Seguidor con el modificador Hostil nos presenta el perfil del Burócrata. El es un dirigente que tiende siempre a guiarse por el término de las reglas y los procedimientos, apoya su responsabilidad en la organización en y la institución, considerando la mayor parte de su ejercicio como ajena a ella; sus acciones están sujetas a la rutina de su trabajo y la aplicación de la norma en aras del cumplimiento del reglamento por encima del espíitu de la norma. Rara vez cambia de condición. ritmo, escenario y estrategia, no le interesa reflexionar sobre el proceso, sólo cumple órdenes y funciones, se limita a la rutina de su obligación, no contraviniendo en lo posible la regla o los procedimientos.

Rata vez corre riesgos y no desea destacarse entre sus otros, aunque disfruta del placer de la dirección. no quiere ni actia intencionadamente para ser lider. Analiza el medio, su dominio y conocimiento sobre las condiciones del establecimiento y del sistema, to convierte en critico permanente al margen de los acontecimientos, sin involucrarse de manera directa en los procesos de cambio y desarrollo. Si se propone una proceso diferente o una idea nueva, suele aducir alguna razón por la cual no dará resultado, aprovechará su condición en la dirección para desecharla o dejarla morir por falta de apoyo, Cuando interactua con un participante de mayor rango o potencial amenazador prefiere aceptar sus opiniones y rechazarlas en otros escenarios sin evidenciarse: en su papel de ejecutor hará poco o nada por adelantar algo en lo que no esté convencido a pesar de haberlo aceptado. o lo desvirtuará en diferentes escenarios si puede hacerlo sin que expresamente lo culpen o lo detecten.
Este perfil de dirigente cuando trata con un miembro que está bajo su dirección. le hace expreso el peso de su condición y del poder que le otorga su cargo, disfruta de la autoridad. En ocasiones expresa resentimiento $\mathrm{e}$ inconformidad por su condición laboral y generalmente contrariedad con el desarrollo y progreso de otros, sobre los que considera no son lo suficientemente merecedores. Busca en general no aparecer protagónico, esquiva la participación, busca no comprometerse con más actividades que las que piensa le corresponden a su cargo Por su falta de flexibilidad es poco recursivo, limita la voluntad y la acción de los participantes. Por su gran conocimiento de la norma, manipula su fabor y el desempeño de los colaboradores. Es idóneo para conocer las fortalezas y debilidades del servicio o sistema del que hace parte. es ágil para almacenar

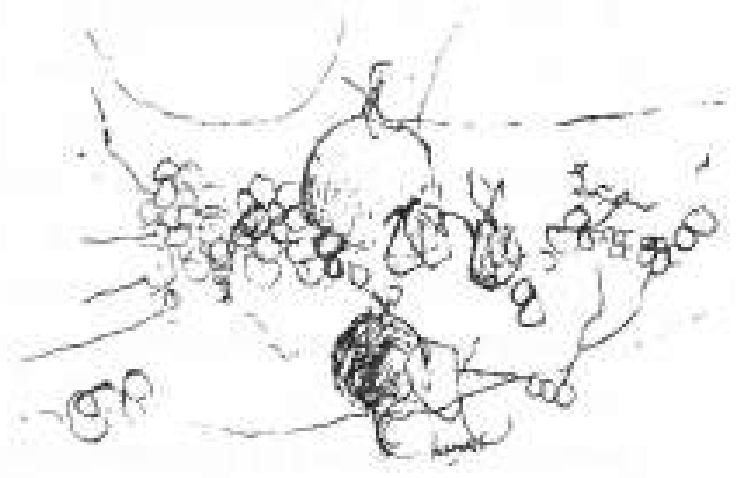

información y ordenar procedimientos. Igualmente como en el anterior perfil. este se presenta como una representación extrema. y aunque toda persona se identifica con algunas caracteristicas de este perfil y asume en mayor grado o menor grado esta tendencia, noexiste dirigente estrictamente de esta condición, que a su vez se encuentre mediado por la polaridad de los otros rasgos y modificadores, que de alguna manera lo equilibran.

La combinación de la tendencia de seguidor conel 
de modificador amistoso. configura la polaridad sociable: es el dirigente que se caracteriza por la etiqueta, las relaciones sociales. la conciliación y los arreglos. Tiende identificarse y congraciarse con los demás supeditando su propia identidad, fundamenta su sentido de autoestima en las señales de reaccion y percepción de los otros, tiende agradar o dar la impresión de ser una persona condescendiente y sociable, aun a riesgo de parecer empalagosa. Es expresivo y comunicativo, trata de acomodarse. seguir las tendencias y las modas. Dado que subordina sus metas a los deseos e impulsos del colectivo. pocas veces toma la iniciativa, colabora y patrocina el trabajo en equipo, su tendencia hacia la camaraderia y la tranquilidad permanente, puede obstaculizar procesus deliberantes, reflexivos y de crecimiento. es poco argumentativo. También cac en estereotipos de identidad y sociabilidad, lejanos a los verdaderos principios de integracion y desamollo personal y colectivo. En su deseo de agradar le resultadificil a veces, conservar limites firmes, mantener las melas o liderar procesos de innovación y cambio que requicran de problematización, responsabilidad y riesgo. de consensos y de disensos. Es un excelente conciliador, relacionista y comunicador.

Finalmente se presenta en la combinacion del rasgo de lider y modificador amistoso. el perfil del dirigente ejecutivo se caracteriza fundarnentalmente por la accion enmarcadia en la visión de la organizacion. Es independiente, animador permanente, es consciente de la institucion y los margenes, respetac interpreta los sentimientos y opiniones en tomo a los objetivos formulados por ta colectividad. acepta alianzas y lineamientos. aunque en la toma de decisiones poco se deja intimidar o influenciar por los actores del proceso.

Tiene en algunos casos exceso de seguridad en si mismo. se afianza en sus condiciones, conocimien- tos y autoconcepto, aunque esto tambien le permite estudiar y apoyar las ideas y puntos de vista que puedien ser opuestas a las-suyas pero que le ayudaran en sus propósitos, su asertividad le permite establecer metas y limites a sus colaboradores, sabe lograr sinergia en su grupo para el cumplimiento de objetivos, fomenta la acción individual y a la vez la mantiene orientada hacia metas institucionales y productivas. El perfil ejecutivo materializa su caracter en la ejecución y la acción, lo que a veces le hace perder visión sobre el mismo proceso y los objetivos sociales, y en emplear sus mejores atributos en acciones instrumentales y activistas, que no logran trascender la misión.

El análisis personológico y actitudinal del dirigente educativo materializado en ocho tendencias. cuatro de ellas primarias de rasgo y modificabilidad. y cuatro de carícter combinatorio, ofrecen un marco de tendencias extremas de referencia al estilo de dirección del ejercicio educativo, una sintesis de estereotipos, ficticios y extremados, que hostigan. afoctan y obligan a la reflexión. que chocan con nuestras comprensiones y recuendos sobre los cuales en algunos casos nos vemos reflejados o ubicamos a nuestros colegas. colaboradores en el escenario educativo.

Cada perfil tiene un conjunto de fortalezas. debilidades, amenazas y oportunidakes. En alguna medida cada uno de nosotros mostramos de cuando en cuando. con mayor o menor fuerza. caracteristcas 


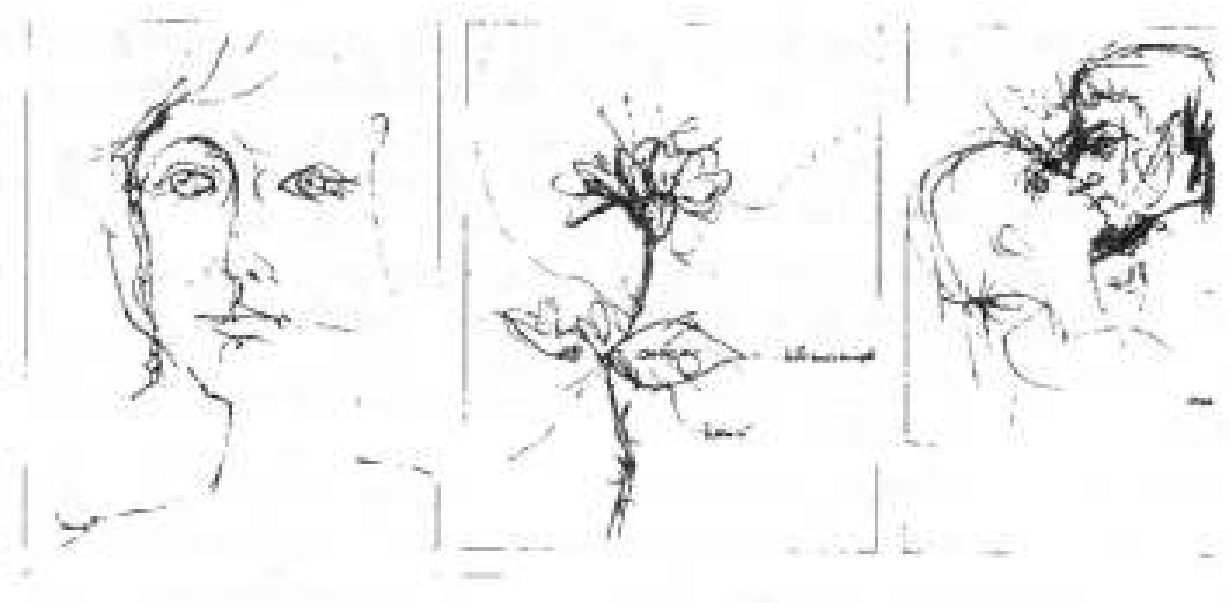

de cierta polaridad. Cada tipo contiene un conjunto especifico de elementos y pormenores que ofrecen distinciones que consideramos repulsivas, contraproducentes, atinentes o útiles en determinadas situaciones, también nos sirven de señal de reflexión y oportunidad de cambio cuando nos reflejamos de manera particular en una polaridad determinada.

Cada perfil es valioso en su sentido de aporte para un momento y una situación especifica. Por ejemplo la imagen de seguridad, empeño y acción del educador de tipo ejecutivo en este caso, lo harain útil en el ejercicio como dirigente en campos cuya meta requiera innovación y posicionamiento; también puede ser útil en ảreas estratégicas de producción, destacadas por su pernmanente liderazgo en el medio. o por el contrario caracterizadas por su escasa significación y que requieren ser rescatadas. El educador de tipo sociable y amistoso puede ser un excelente dirigente de relaciones entre grupos heterogéneos e intragrupos, relacionistas de areas $\mathrm{y}$ proyectos. puede canalizar esfuerzos interistitucionales e interdisciplinarios, puede articular procesos de transformación y de cambio. La tendencia burocratica puede ser aprovechada en la supervision. seguimiento y control de procesos, en la administración de recursos, en la estabilización de procesos, $y$, aún, algunos elementos de la polaridad dictatorial pueden contribuir a la superación de crisis y a la obtención de logros específicos en el cual el factor de empeño y determinación sea preponderante; también puede servir como simple señal para la reflexión y el cambio personal.

El maestro es el fruto de una combinación de afectos, emociones, saberes, deseos, voluntades. cos. tumbres y actitudes, es necesario elaborar un entramado entre las diferentes tendencias polares y examinarlas a la luz del maestro como dirigente institucional o académico, con la aceptación, empatia, y comunicación con sus alumnos; es necesario recuperar al maestro como actor social. coprotagonista de los procesos de enseñanza y aprendizaje; es im. prescindible articular y correlacionar el estilo de dirigencia del maestro con la imagen y representación que se hace el estudiante; buena parte de la participación, el desempeño y el logro en el escenirio educativo nacen de la relaciỏn fructifera de sus actores, y especialmente de la relación con el maestro. Es evidente en los procesos de comunicación. la diferencia existente entre lo que piensa el maestro respecto a su actitud. conducta y comportaniento. a la que refleja en el estudiante y en la institución". Es preciso develar la congruencia entre los estilos 
de dirigencia y la facilitación y acompañamiento que ofrece el maestro frente a sus estudiantes.

En sintesis, es importante examinar cuál es el tipo de dirigente que proyecta el profesor. qué compatibilidad existe con su papel pedagógioo de orientador. que rapport ofrece y cómo influye en su proceso de formación y desempeño. En los procesos de aprendizaje es fundamental el juego que ejerce el agente educativo, el cual lleva implicitasmaneras particulares de abordar la acción y acercarse como acompañante: dependiendo de estas formas se facilitarăn. de mejor manera. los procesos de aprehensión. comprensión e interiorización del conocimiento: el primer compromiso como maestro es conocerlas y reflexionar sobre ellas, establecer la congruencia con su quehacer y su intencionalidad pedagópica.

Se ofrece aqui como ejemplo desde una perspectiva de polaridades, la oportunidad de reflexionar sobre nuestra forma de facilitar y acompañar los procesos. La presentación de estereotipos de choque, extremos e incompatibles, cada uno por si solo, ajeno a la verdadera dimensión de ser humano, sólo representa la oportunidad para que desde nuestra reflexión e interioridad, recreemos la práctica educativa cotidiana y con ello develemos el sello de nuestra propia identidad. *
' GONZAI.EZ, Carlos, Gerencia Integral Creativa. En: Deciseon Administrativa. No.2. Abril-Sanis IOpy. U. Nacional de Colomba. Sede Manizaies

'SALLENAVE Jean Paul La Gerentia Integral Editorial Norma. Bogotá. 1994

'DE PRADO. David. Manual de Activación Creativa. Centro de Estudios LUBRICAN. Compostela 1987

${ }^{4}$ SEFCHOVICH, G. y WAISBUD. G. Hacia uns Pedagogia de la creatividad. En: Creatividad para adultos. Sistema de Actitudes y Responsabilidades del faciliador y del Participante. Trillas. México, 1993.

' GONZALEZ. America. Como propiciar la Creatividad. Fondo Editorial Tropycus. Caracas, 1992

'CHICA. Ruben Dario. El Maestro en la Dirigencia Educativa e limagen de aceptación del educatito en el tiscesario Escolar CINDE Manizales 1909

' GRETZ, Karl y DROZDECK. Steven. A proveche la Crta. tividad de sus Empleados. Editorial Mc. Graw Hill. México. 1994

*Ibid. Pag 107

"Op.Cit. Chica, Ruben Dario, 1999. 